\title{
Epidemiological Analysis for medical records of Veterinary Teaching Hospital, University of Mosul during 2017 to 2019
}

\author{
M.O. Dahl ${ }^{1} \mathbb{D}^{\mathrm{D}}$, O.Kh. Hamdoon ${ }^{2}$ and O.N. Abdulmonem ${ }^{2}$
}

${ }^{1}$ Department of Internal and Preventive Medicine, College of Veterinary Medicine, University of Mosul, ${ }^{2}$ Veterinary doctors, private sectors, Mosul, Iraq

\begin{tabular}{l} 
Article information \\
\hline Article history: \\
Received May 17, 2020 \\
Accepted June 19,2020 \\
Available online June 24, 2021 \\
\hline Keywords: \\
Epidemiological analysis \\
Medical records \\
Veterinary hospital \\
Clinical cases \\
\\
\hline Correspondence: \\
M.O. Dahl \\
mdahl@ uomosul.edu.iq
\end{tabular}

\begin{abstract}
This analysis aimed to (i) report diseases of animals received at the Veterinary Teaching Hospital, University of Mosul between years 2017 and 2019, and (ii) examine whether its records can be used in studying the factors associated with different diseases. In this analysis, medical records of 1,280 cases examined and diagnosed at the internal medicine section and/or clinical pathology laboratory were used. Odds of diseases as a function of different factors were modeled using conditional logistic regression. Results revealed that the number of cases was increased in 2018-2019 compared to the previous academic year. The minimum number of cases was received in autumn, and the maximum was in summer. The most received cases were from areas located at the south inside Mosul city. The most received cases were generally gastrointestinal disturbances, blood parasites, and respiratory infections. Skin affections were also frequently received. Modeling diseases in ruminants indicated that blood parasites infection were higher in old ages compared to younger, greater in spring, summer, and autumn compared to winter, and more in city countryside compared to its inside. Gastrointestinal parasites infection was greater in old ages compared to younger, higher in summer compared to autumn, winter, and spring. Respiratory infections were higher in young animals compared to older ages, and greater in summer compared to autumn and spring. Enteritis of different causes was higher in young animals compared to older ages, and greater in winter compared to summer. In conclusion, records of this hospital are useful for studying animal diseases.
\end{abstract}

DOI: $10.33899 /$ ijvs.2020.127141.1468, (C2021, College of Veterinary Medicine, University of Mosul. This is an open access article under the CC BY 4.0 license (http://creativecommons.org/licenses/by/4.0/).

\section{Introduction}

The Veterinary Teaching Hospital is one of essential facilities operated by the College of Veterinary Medicine University of Mosul, Iraq, for training of fifth and fourth years' veterinary students. It was established in 1989 inside the main campus of the University of Mosul, and included five main sections including Internal medicine, clinical pathology laboratory, surgery, theriogenology, and poultry diseases, in addition to a pharmacy, lecture hall, and administration room. The hospital works during the official hours of the University of Mosul, and receives different clinical cases of cattle, sheep, goats, buffaloes, horses, dogs, cats, and poultry from different areas, majority from Mosul and its countryside. These cases are examined, diagnosed, and treated by the college faculty and trainee students. The hospital uses traditional paper-based records to document cases examined, diagnosed, and treated inside the hospital building.

Different clinical cases are examined and diagnosed at internal medicine section and/or clinical pathology laboratory; however, only one study used records of the hospital to investigate these cases in sheep and goats (including 6,152 sheep and 397 goats) between January 2007 and October 2010 (1). In that study, the most frequent infections were gastrointestinal disturbances, respiratory 
infections, and then skin affections, and there were differences between sheep and goats in types of the infection in different seasons of the year (for instance, the greatest gastrointestinal parasites infections were reported in summer in sheep, but in autumn in goats). Similarly, in that study, the highest respiratory infections were reported in spring and winter in sheep, but in autumn in goats. Nevertheless, more detailed study is required to interpret such results. On the other hand, cattle cases are considered the most cases received at the hospital of interest; however, records of these cases have not been studied. Several studies have reported numerous infections in cattle, for instance gastrointestinal parasites (2), blood parasites (3), and brucellosis (4). Therefore, the objectives of the current epidemiological analysis were to (i) report diseases of animals received at the Veterinary Teaching Hospital - University of Mosul between years 2017 and 2019, and (ii) examine whether its records can be used in studying the factors associated with different diseases.

\section{Materials and methods}

\section{Study animals}

Records of 1,280 cases examined and diagnosed at the internal medicine section and/or clinical pathology laboratory of the Veterinary Teaching Hospital at the University of Mosul were used in the current survey. Studied animals were 652 cattle, 398 sheep, 70 goats, 29 buffaloes, 17 horses, 60 dogs, 46 cats, and 8 miscellaneous animals. Pertinent animals were raised inside Mosul city and its countryside.

\section{Cases classification and identification}

Cases were classified into 11 general types diagnosed clinically or at the laboratory of the hospital, including: (i) gastrointestinal disturbances, which included parasitic infection, tympani, simple indigestion, acidosis, foreign body syndrome, vagal indigestion, enteritis or gastroenteritis, and stomatitis or pharyngitis; (ii) respiratory infections either upper or lower part; (iii) blood parasites; (iv) Abortion; (v) limbs affections including foot rot and arthritis; (vi) mastitis; (vii) metabolic disorders including parturient paresis and ketosis; (viii) skin affections including dermatitis and different ectoparasites; (ix) nutritional deficiency; (x) urinary tract infection; (xi) eye infection. Miscellaneous affections that were not frequently received, for instance snake bit and otitis media, were added as other one type of cases.

\section{Data collection}

Hospital records were used to collect the following data: academic year, season, geographical area of the owner, sex and age of the animal. In this study, two academic years were included: 2017-2018 and 2018-2019, where each started on Oct. $1^{\text {st }}$ and ended on Sept. $30^{\text {th }}$ of the next year. Seasons were identified on a basis of mean of maximum and minimum environmental temperatures $\left({ }^{\circ} \mathrm{C}\right)$ for each month in Mosul city obtained from Iraqi meteorological organization and seismology (station 608, Mosul). Seasons included autumn $\left(\min 10-20^{\circ} \mathrm{C}, \max 20-35^{\circ} \mathrm{C}\right.$; October and November); winter $\left(\min <10^{\circ} \mathrm{C}, \max <20^{\circ} \mathrm{C}\right.$; December, January, February); spring $\left(\min 10-20^{\circ} \mathrm{C}, \max 20-35^{\circ} \mathrm{C}\right.$; March, April, May); and summer $\left(\min >20^{\circ} \mathrm{C}, \max >35^{\circ} \mathrm{C}\right.$; June, July, August, September). On the other hand, geographical area of the owner was classified according to their location to the pertinent hospital, and included: countryside north, inside the city north, inside the city south, and countryside south. In addition, sex of the animals included male and female. Finally, age of the animals was categorized into: (i) younger than 1-year-old and (ii) 1-yearold and older.

\section{Statistical analysis}

Frequencies and percentages of cases were calculated according to the academic year, species of the animal, season, and geographical area. On animal species level, frequencies and percentages of cases were also calculated. On the other hand, particular infections (including blood parasites infection, gastrointestinal parasites infection, respiratory infection, enteritis) in ruminants with sufficient data for analysis were analyzed using the conditional logistic regression to model the odds of these diseases as a function of available epidemiological factors. A total of 17 horses was not sufficient for such analysis, and data of dog and cats included considerable missing, particularly for age, prevented such analysis, too.

The conditional logistic regression process firstly included stratifying and matching the infection (yes, no) according to animal species (i.e., cattle, sheep, goats, and buffaloes). Next, variable selection method was used as a model building strategy (5) as the following: factors associated with selected diseases were initially screened by use of univariable conditional logistic regression to identify variables for the multivariable analysis (i.e., variables with a value of $\mathrm{P} \leq 0.20$ ). In this analysis, age was significantly associated with sex $\left(\chi^{2} p\right.$-value $\left.<0.01\right)$. That is, the older age group included more females as they are used in milk and offspring production. In this study, age was considered most biologically plausible variable; thus, variable for sex was not considered for further modeling. Subsequently, multivariable analysis was performed using a manual forward selection technique by adding one variable at a time and assessing the model goodness-of-fit using the likelihood ratio test statistic. The odds ratio (OR) was used as an epidemiologic measure of association between the factors and studied diseases, where the OR of 1 indicated no association, while the greater the departure of the OR from 1 , the stronger the association was between the factor and the disease (6). Factors retained in final models were examined for confounding by assessing changes in OR (i.e., $\geq 20 \%$ ) of 
the remaining variables in the model. In the final models, variables with a value of $\mathrm{P} \leq 0.05$ (2-tailed) were considered significant, and the adjusted OR and 95\% confidence interval were reported. Statistical analyses were performed using STATA 13.0 (StataCorp, College Station, TX).

\section{Results}

\section{Frequencies of the Cases}

The total number of cases was increased in the academic year 2018-2019 compared to the previous one, and that increase included all species of the animals (Figure 1). The minimum number of cases was received in autumn, and the number was increased in a linear mode to reach the maximum in the summer in both academic years (Figure 2). The most received cases were from areas located at the south of the hospital inside Mosul city (Figure 3). The most received cases were generally characterized by gastrointestinal disturbances and infections, blood parasites infection, and different respiratory infections (Figure 4). Skin affections were also frequently received (Figure 4). On animal species level, blood parasites infection were the most frequent cases of cattle, gastrointestinal disturbances and respiratory infections were the most continual cases of sheep and goats, and gastrointestinal disturbances were the most cases of buffaloes, horses, dogs and cats (Figure 5).

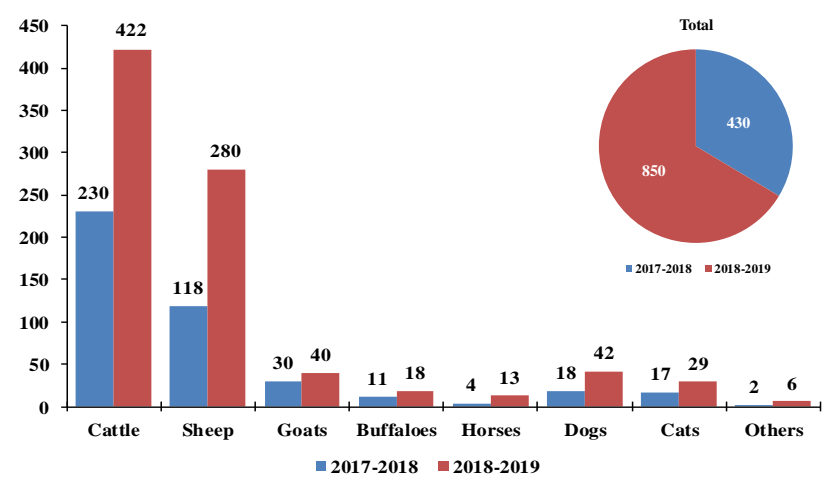

Figure 1: Number of cases examined and diagnosed at the internal medicine section and/or clinical pathology laboratory of the Veterinary Teaching Hospital at the University of Mosul between Oct. $1^{\text {st }}, 2017$ and Sept. 30 2019.

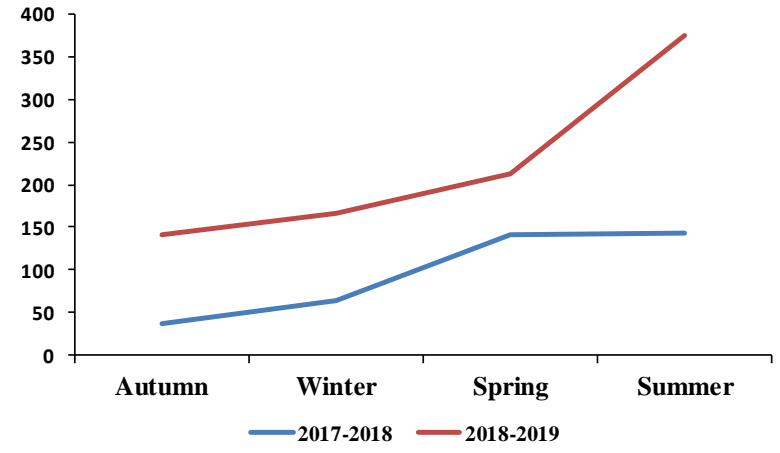

Figure 2: Number of cases examined and diagnosed at the internal medicine section and/or clinical pathology laboratory of the Veterinary Teaching Hospital at the University of Mosul between Oct. $1^{\text {st }}, 2017$ and Sept. $30^{\text {th }}$, 2019 according to the season.

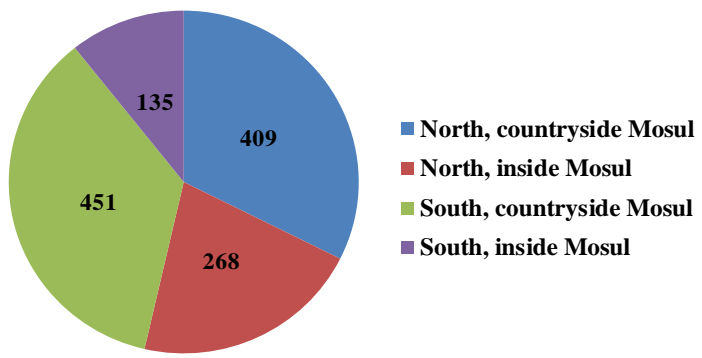

Figure 3: Number of cases examined and diagnosed at the internal medicine section and/or clinical pathology laboratory of the Veterinary Teaching Hospital at the University of Mosul between Oct. $1^{\text {st }}, 2017$ and Sept. 30 ${ }^{\text {th }}$, 2019 according to geographical area of the animal owner.

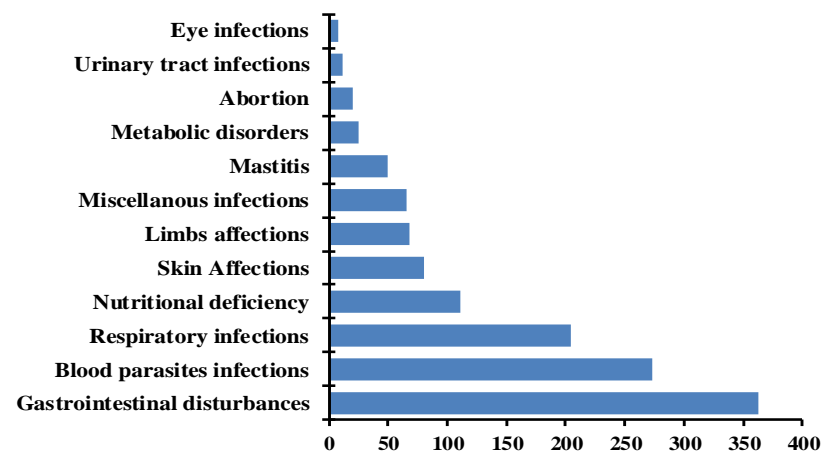

Figure 4: Number of cases examined and diagnosed at the internal medicine section and/or clinical pathology laboratory of the Veterinary Teaching Hospital at the University of Mosul between Oct. $1^{\text {st }}, 2017$ and Sept. $30^{\text {th }}$, 2019 according to the type of the infection or disturbance regardless to the species of the animals. 

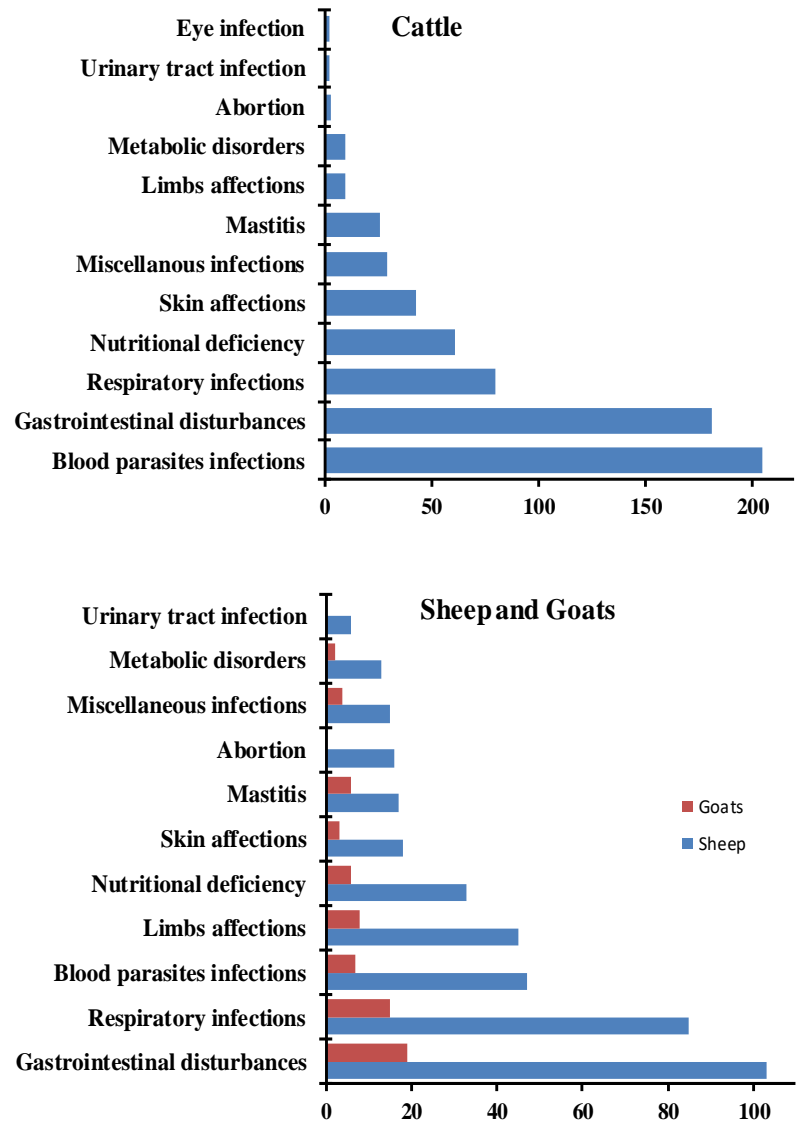

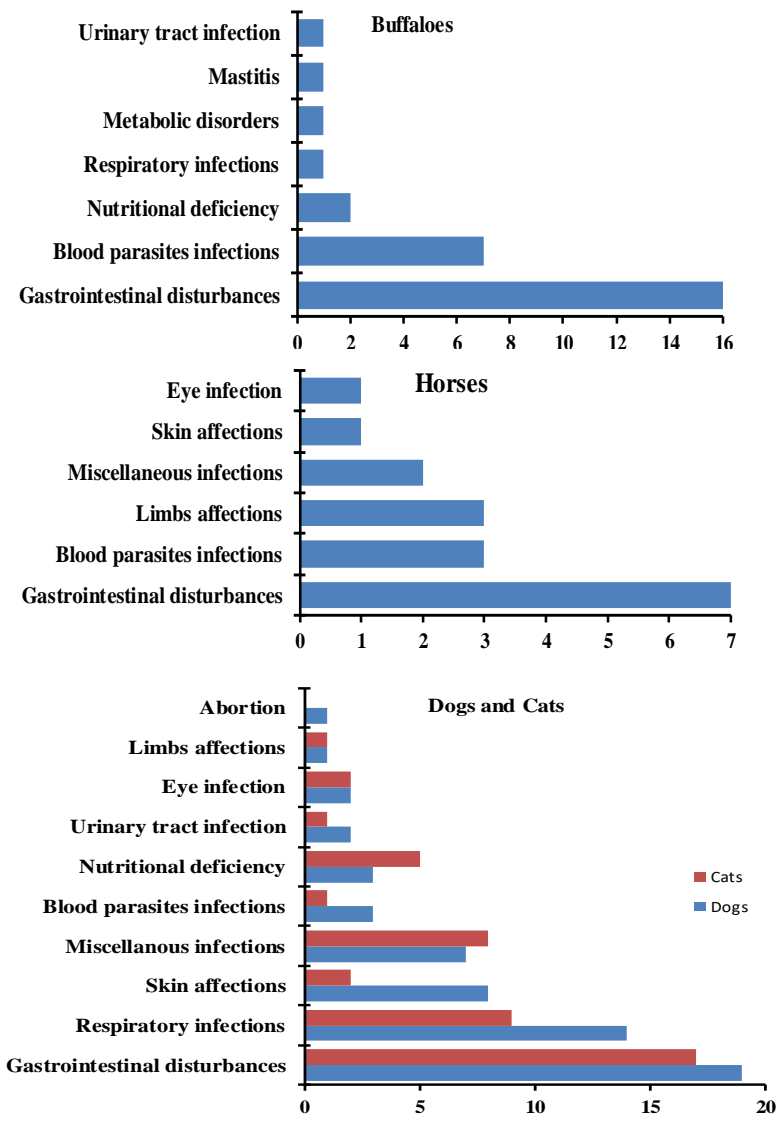

Figure 5: On animal level number of cases examined and diagnosed at the internal medicine section and/or clinical pathology laboratory of the Veterinary Teaching Hospital at the University of Mosul between Oct. $1^{\text {st }}, 2017$ and Sept. $30^{\text {th }}, 2019$.

\section{Factors associated with blood parasites infection in ruminants}

The univariable analysis revealed that blood parasites infection in ruminants was associated with age and sex of the animals, season, and geographical area. The final model indicated that the odds of blood parasites infection in ruminants were two times higher in 1-year-old and older age group compared to those younger than 1-year-old, adjusted for season and geographical area (Table 1). Furthermore, the odds of the infection were two to four times greater in spring, summer, and autumn compared to winter; and two times more in autumn, compared to spring and summer adjusted for age and geographical area (Table 1). Moreover, the odds of the infection were one and half times higher inside Mosul city compared to its countryside areas adjusted for age and season (Table 1).
Table 1: Final conditional logistic regression model for epidemiologic factors associated with blood parasites infection in ruminants

\begin{tabular}{lccc}
\hline Variable & $\begin{array}{c}\text { Adjusted } \\
\text { Odds } \\
\text { Ratio }\end{array}$ & $\begin{array}{c}95 \% \\
\text { Confidence } \\
\text { Interval }\end{array}$ & $P$-value \\
\hline $\begin{array}{l}\text { Age } \\
\text { < 1-year-old }\end{array}$ & - & - & - \\
$\begin{array}{l}\text { 1-year-old } \\
\text { Season }\end{array}$ & 2.22 & $1.55,3.19$ & $<0.01$ \\
Spring vs. winter & 2.15 & $1.32,3.51$ & $<0.01$ \\
Summer vs. winter & 2.30 & $1.45,3.65$ & $<0.01$ \\
Autumn vs. winter & 4.80 & $2.82,8.17$ & $<0.01$ \\
Autumn vs. spring & 2.23 & $1.45,3.43$ & $<0.01$ \\
Autumn vs. summer & 2.09 & $1.40,3.11$ & $<0.01$ \\
Summer vs. spring & 1.07 & $0.77,1.50$ & 0.70 \\
Geographical Area & & & \\
South inside Mosul & - & - & - \\
North inside Mosul & 1.08 & $0.71,1.65$ & 0.71 \\
North countryside Mosul & 1.47 & $1.05,2.06$ & 0.03 \\
South countryside Mosul & 1.87 & $1.19,2.93$ & $<0.01$ \\
\hline
\end{tabular}




\section{Factors associated with gastrointestinal parasites infection in ruminants}

The univariable analysis indicated that gastrointestinal parasites infection in ruminants was associated with age and sex of the animals, season, and was higher in north countryside area. The final model showed that the odds of gastrointestinal parasites infection were four times greater in 1 -year-old and older age group compared to those younger than 1-year-old, adjusted for season and academic year (Table 2). In addition, the odds of infection were higher in summer compared to autumn, winter, and spring, adjusted for age and academic year (Table 2), without statistical differences between infection rates in autumn, winter, and summer. Further, the infection was increased in 2018-2019 compared to the previous year (Table 2).

\section{Factors associated with respiratory infection in ruminants}

The univariable analysis indicated that respiratory infection in ruminants was associated with age and sex of the animals, season, and was higher in south inside Mosul city. The final model showed that the odds of respiratory infection in ruminants were 3 times greater in younger than 1-year-old compared to those 1-year-old and older, adjusted for season and geographical area (Table 3). Moreover, the odds of the infection were higher in summer compared to autumn and spring, but not winter, adjusted for age and geographical area (Table 3). The model revealed no significant statistical differences in the infection between geographical areas (Table 3)

Table 2: Final conditional logistic regression model for epidemiologic factors associated with gastrointestinal parasites infection in ruminants

\begin{tabular}{lccc}
\hline Variable & $\begin{array}{c}\text { Adjusted } \\
\text { Odds } \\
\text { Ratio }\end{array}$ & $\begin{array}{c}95 \% \\
\text { Confidence } \\
\text { Interval }\end{array}$ & $P$-value \\
\hline $\begin{array}{l}\text { Age } \\
<1 \text {-year-old }\end{array}$ & - & - & - \\
$\begin{array}{l}\text { 1-year-old } \\
\text { Season }\end{array}$ & 4.32 & $1.94,9.63$ & $<0.01$ \\
Summer & - & - & - \\
Autumn & 0.27 & $0.12,0.61$ & $<0.01$ \\
Winter & 0.31 & $0.16,0.58$ & $<0.01$ \\
Spring & 0.41 & $0.24,0.71$ & $<0.01$ \\
Academic Year & & & - \\
$2017-2018$ & - & - & - \\
$2018-2019$ & 1.77 & $1.07,2.92$ & 0.03 \\
\hline
\end{tabular}

Factors Associated with signs of enteritis in Ruminants

The univariable analysis indicated that enteritis in ruminants was associated with age and sex of the animals. The final model revealed that the odds of enteritis in ruminants were six times higher in younger than 1-year-old compared to those 1-year-old and older, adjusted for season (Table 4). In addition, the odds of enteritis were two times greater in winter compared to summer, adjusted for age (Table 4), without statistical differences between infection rates in summer, autumn, and spring.

Table 3: Final conditional logistic regression model for epidemiologic factors associated with respiratory tract infection in ruminants

\begin{tabular}{lccc}
\hline Variable & $\begin{array}{c}\text { Adjusted } \\
\text { Odds } \\
\text { Ratio }\end{array}$ & $\begin{array}{c}95 \% \\
\text { Confidence } \\
\text { Interval }\end{array}$ & $P$-value \\
\hline Age & & & \\
$\geq 1$-year-old & - & - & - \\
$\begin{array}{l}\text { < } \text {-year-old } \\
\text { Season }\end{array}$ & 3.29 & $2.32,4.68$ & $<0.01$ \\
Summer & & & - \\
Autumn & - & - & - \\
Winter & 0.53 & $0.30,0.95$ & 0.03 \\
Spring & 0.79 & $0.50,1.26$ & 0.33 \\
Geographical Area & 0.65 & $0.43,0.97$ & 0.03 \\
North inside Mosul & & & \\
South inside Mosul & - & - & - \\
North countryside Mosul & 1.58 & $0.99,2.52$ & 0.06 \\
South countryside Mosul & 0.87 & $0.65,1.73$ & 0.81 \\
\hline
\end{tabular}

Table 4: Final conditional logistic regression model for epidemiologic factors associated with enteritis in ruminants

\begin{tabular}{lccc}
\hline Variable & $\begin{array}{c}\text { Adjusted } \\
\text { Odds } \\
\text { Ratio }\end{array}$ & $\begin{array}{c}95 \% \\
\text { Confidence } \\
\text { Interval }\end{array}$ & $P$-value \\
\hline Age & & & \\
$\geq 1$-year-old & - & - & - \\
< 1 -year-old & 6.26 & $3.67,10.66$ & $<0.01$ \\
Season & & - & - \\
Summer & - & - & 0.58 \\
Autumn & 1.29 & $0.53,3.14$ & 0.05 \\
Winter & 2.04 & $1.01,4.12$ & 0.17 \\
Spring & 1.54 & $0.83,2.85$ & \\
\hline
\end{tabular}

\section{Discussion}

This study provided an overview about diseases and disorders affect different species of animals in Mosul city, Iraq and its countryside throughout records of the Veterinary Teaching Hospital, University of Mosul. The study examined exposure and risk factors associated with diseases of interest. Potential confounding effects of such factors on studied diseases were reduced by matching species of animals and statistically controlling for factors that can affect incidence of such diseases by use of multivariable modeling procedure. 


\section{Frequencies of the cases}

The total number of cases reported in current survey was increased in the academic year 2018-2019 compared to the previous one. This increase might not mean more spread of diseases between animals in the city, but it could be attributable to return of more owners to their areas after the military actions happed in the area between 2014 and 2017. In a previous study used records of this hospitable between 2007 and 2010 (1), the total reported number of sheep and goats was twice of what has been reported in this current study for same species of animals. In this survey, the minimum number of cases was received in autumn, and the number was increased in a linear mode to reach the maximum in the summer in both academic years. Summer of the city is hot and dry, which constitutes a stress factor that has negative impact of animals' heath such as causing metabolic changes, oxidative damage, and immune suppression (7). Additional potential factor that can increase incidence of diseases in summer, particularly blood parasites, is increase of tick activity that can spread the infection between animals (8). Current survey revealed that the most received cases were from areas located at the south of the hospital inside Mosul city. One reason to this result is that the hospital of interest is located at the north part of the city, which increased the possibility of receiving more animals from the south of inside the city. However, the total number of the cases was generally greater from areas at the north of the city. A report of location of animals' herds in the area is important for control programs preparation and implementation.

This survey indicated that the most received cases were generally characterized by gastrointestinal disturbances and infections, blood parasites infection, and different respiratory infections. Skin affections were also frequently received. This result is in line with what has been reported in sheep and goats using records of the same hospital (1). It has been indicated that gastrointestinal disturbances are the most frequent cases that can a veterinarian see in the career (9). Several studies reported different gastrointestinal disturbances and infection in the animals in Mosul, particularly gastrointestinal parasites in sheep (10), goats (11), horses (12), buffaloes (13), and cattle $(2,14)$. On the other hand, blood parasites have been reported in different animals including sheep (15), horses (16), goats (10), and calves (3). In addition, different skin affections were reported (11,17-19).

\section{Factors associated with blood parasites infection in ruminants}

The current study indicated that the odds of blood parasites infection in ruminants were two times higher in 1year-old and older age group compared to those younger than 1 -year-old. It has been reported that blood parasitic infection and its severity increase with the age, although young animals are also susceptible to the infection, despite the potential resistance that they have to such infection due to passive immunity (8). On the other hand, the odds of the infection were greater in spring, summer, and autumn compared to winter; and higher in autumn, compared to spring and summer. The activity of the vectors, i.e., ticks, is increased in warm seasons, although hot and dry summer allow only one life cycle of ticks (8). One reason that the infection rate in autumn was higher than that for summer in this study is that the infection was occurred in summer; however, it was diagnosed in autumn as local owners of the animals usually do bring their animals to the hospital when the cases are exacerbated. On the other hand, the odds of the infection were higher inside Mosul city compared to its countryside areas. Potential reason for this difference is the variation in animals' husbandry between the areas which could expose the animals in countryside to ticks. However, this result requires more investigation.

\section{Factors associated with gastrointestinal parasites infection in ruminants}

The current study showed that the odds of gastrointestinal parasites infection were greater in 1-year-old and older age group compared to those younger than 1-year-old. Literatures are varying in report of gastrointestinal parasites according to age. For instance, no differences have been reported in sheep and goats (20), and cattle and sheep (21). Nevertheless, results of the current work is in line with what has been reported in cattle and buffaloes that age group 1year and older show higher infection rate with gastrointestinal parasites compared to those of younger than 1 -year-old (22), in contrast to what has been found in goats (23). On the other hand, the odds of infection were higher in summer compared to autumn, winter, and spring. In addition, no statistical differences were indicated between infection rates in autumn, winter, and summer. The previous study revealed that the infection of sheep and goats with gastrointestinal parasites was high in summer (1). It is known that the infectious stages require warm and dry season for development (23). However, in study animals, the infection could have been occurred in spring but diagnosed in summer; as previously mentioned that local owners of the animals usually do bring their animals to the hospital when the cases are exacerbated. Low infection rate in autumn in current data could be explained that the hot and dry summer reduced the infection spread, while the cold weather of winter is unfavorable for infectious stages development. More investigations are required to study this pattern of infection in local animals.

\section{Factors associated with respiratory infection in ruminants}

In this study, the odds of respiratory infection in ruminants were greater in younger than 1-year-old compared to those 1-year-old and older. This infection pattern could be attributable to the fact that the immune system of young 
animal is not fully developed against infections as that for older animals which exposed to different infection and developed different antibodies (24). This result is in line with what was previously reported in sheep and goats using records of the same hospital (1), although the two studies vary in the method of categorizing the variable of age. On the other hand, the odds of the infection were higher in summer compared to autumn and spring, but not winter. The stress of hot and dry environment of summer can decrease the immunity of the animals, and the cold environment of winter facilitates development of respiratory infections (24).

\section{Factors associated with enteritis in ruminants}

Current study indicated that the odds of enteritis of different causes in ruminants were higher in younger than 1year-old compared to those 1-year-old and older. The result of this work agrees with the previous investigation on sheep and goats (1). Young animals infected with different bacterial and viral diseases that are associated with enteritis $(9,25)$. On the other hand, the odds of enteritis were greater in winter compared to summer. The data did not reveal statistical differences between infection rates in summer, autumn, and spring. Animals in cold weather tend to grouped to each other; a satiation could increase the chance of infection (25).

\section{Study limitation}

The current investigation was conducted on hospital records, in which we have no role of their content; as additional epidemiologic factors can be studied such as breed, body weight, or most prominent clinical findings which have not been included in the record. In addition, age of the animals was not exactly determined; thus, we could not categorize the variable for age more than two categories. More age group categories could reveal more information about the effect of age on such diseases. Finally, we did not have control on missing information in some animals' records.

\section{Conclusions}

The current analysis concluded that the gastrointestinal disturbances, blood parasites, and respiratory infections are the most frequent occurrence disturbances and infections in animals located inside Mosul city and its countryside, summer is the most season can negatively affect animals' health, and records of the Veterinary Teaching Hospital, University of Mosul can be used in studying some of epidemiologic factors associated to diseases of animals. Adding more information pertaining the cases, such as animal breed, body weight or body condition score, most prominent clinical findings, number of animals the owner has and number of affected animals could improve research used records of this hospital. Finally, electronic-based records system is highly recommended to this hospital.

\section{Acknowledgement}

The authors thank the administration of the Veterinary Teaching Hospital, College of Veterinary Medicine at the University of Mosul, Iraq, for making the records available.

\section{Conflict of interest}

The authors declare that there is no conflict of interest regarding the publication of this work.

\section{References}

1. Mohamed HA. Epidemiological surveillance of clinical diseases in sheep and goats recorded in Veterinary Teaching Hospital, College of Veterinary Medicine, University of Mosul. Bas J Vet Res. 2011;10(2):1-10. [available at]

2. Hasan MH, Khalaf WK. Diagnostic study of parasitic worms and intestinal protozoa in Cattle. Assiut Vet Med J. 2013;59(136):1-9. [available at]

3. Alssad KM, Suleiman EG, Al-Obaidi QT. Theileriosis in newborn calves in Mosul, Iraq. Bas J Vet Res. 2013;12(1):265-274. [available at]

4. Al-Farwachi MI, Al-Iraqi OM, Al-Hankawe OKh, Abdul-Majeed MO. Using of competitive ELISA in detection of brucella antibodies in cattle sera in Mosul city, Iraq. Iraqi J Vet Sci. 2009;23(2):97-103. DOI: 10.33899/ijvs.2009.5739

5. Hosmer DW, Lemeshow S. Applied logistic regression. Wiley Series in Probability and Statistics. $2^{\text {nd }}$ ed. New York: John Wiley and Sons; 2000.

6. Dohoo I, Martin W, Stryhn H. Veterinary epidemiologic research. Canada: AVC Inc; 2003. 121-163 p.

7. Lacetera N. Impact of climate change on animal health and welfare. Anim Front. 2019;9(1):26-31. DOI: 10.1093/af/vfy030

8. Radostits OM, Clive CG, Hinchcliff KW, Constable PD. Veterinary medicine: A textbook of the diseases of cattle, horses, sheep, pigs, and goats. $10^{\text {th }}$ ed. USA: Elsevier; 2007. 1483-1584 p.

9. Belknap EB, Navarre CB. Differentiation of gastrointestinal diseases in adult cattle. Vet Clin North Am Food Anim Pract. 2000;16(1):59-86. DOI: 10.1016/S0749-0720(15)30137-7

10. Sulaiman EG, Talib Q, Daham E, Arslan SH. Study of some eggs and oocytes of internal parasites in sheep in Mosul. Iraqi J Vet Sci. 2005;19(1):21-32. DOI: 10.33899/ijvs.2005.37275

11. Al-Obaidi QT. Clinical, haematologica studies of single infection with some blood protozoa, endo and ecto-parasite in native goats in Mosul. Iraqi J Vet Sci. 2006;20(2):283-298. DOI: 10.33899/ijvs.2006.45786

12. Alsaad KM, Abdul-Majeed MO. Clinical and pathological effects of gastrointestinal and lung worms on draught horses in Mosul. Iraqi J Vet Sci. 2006;20(1):71-80. DOI: 10.33899/ijvs.2006.45786

13. Alsaad KM, Abdul-jabbar OM. Clinical, hematologic and biochemical effects of gastrointestinal and lung worm's infection in local buffaloes in Mosul. Bas J Vet Res. 2007;6(2):23-38. [available at]

14. Abdulhameed MA, Al-Obaidy QT, Esmaeel SA, Hussain KhJ. Clinical and therapeutic study of gastrointestinal parasites in fedlot calves in Goggeli region. Iraqi J Vet Sci. 2012;26(1):23-27. DOI: 10.33899/ijvs.2012.35203

15. Al-Obaidi QT, AlSaad KM. Clinical, haematological and pathological studies of naturally infected sheep with Theileria hirci. Iraqi J Vet Sci. 2004;18(2):165-175. [available at]

16. Al-Saad KM, Al-Mola GM. Clinical and pathological study of equine babesiosis in draught horses in Mosul. Iraqi J Vet Sci. 2006;20(1):89101. DOI: $10.33899 /$ ijvs.2006.45787

17. Al-Farwachi MI, Al-Badrani BA, Al-Oubid WA. Prevalence of mange in water buffaloes at Mosul area (Iraq). $11^{\text {th }}$ Sci Cong Fac Vet Med Assiut Uni, Egypt. 2004;36-40. [available at] 
18. Al-Farwachi MI, Al-Mola ED, Al-Obaidi WA. The variation in the effect of lice infestation between goats and sheep in Mosul area. Iraqi $\mathrm{J}$ Vet Sci. 2006;20(2):203-210. [available at]

19. Al-Lahaibi BY, Al-Taee AF. Detection of some species of lice and ticks infestation on local buffalo in Mosul city. Iraqi $\mathrm{J}$ Vet Sci. 2018;32(2):43-50. DOI: 10.33899/ijvs.2019.153876

20. Dappawar MK, Khillare BS, Narladkar BW, Bhangale GN. Prevalence of gastrointestinal parasites in small ruminants in Udgir area of Marathwada. J Entomol Zool Stud. 2018;6(4):672-676. [available at]

21. Pinilla León JC, Delgado NU, Florez AA. Prevalence of gastrointestinal parasites in cattle and sheep in three municipalities in the Colombian Northeastern Mountain, Vet World. 2019;12(1):48-54. DOI: 10.14202/vetworld.2019.48-54

22. Sohail M, Hamidullah, Sajid M, Shoaib M, Malik M. Prevalence of Gastrointestinal Parasites in Large Ruminants (Bovines) in District Abbottabad, Khyber Pakhtunkhwa, Pakistan. EC Vet Sci. 2019;4.4:234-240. [available at]

23. Regea G. Prevalence of major gastrointestinal tract parasite of cattle at municipal abattoir of Jimma Town, Oromia, South Western Ethiopia. Vet Med Open J. 2019;4(1):36-44. DOI: 10.17140/VMOJ-4-134

24. Muheet, Malik HU, Parray OR, Bhat RA, Yatoo MI. Seasonal and periodic rhythmicity of respiratory infections in small ruminants. Biol Rhyth Res. 2019;1-9. DOI: 10.1080/09291016.2019.1576283

25. Constable PD, Hinchcliff KW, Done SH, Gruenberg W. Veterinary Medicine: A Textbook of the Diseases of Cattle, Horses, Sheep, Pigs, and Goats. $11^{\text {th }}$ ed. USA: Elsevier; 2017. 599 pp.

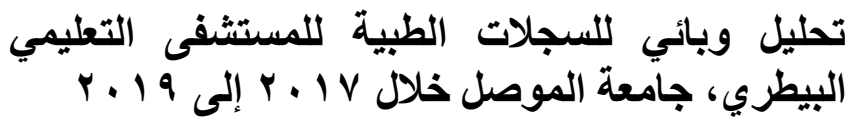

محمد أسـامة دحل، عمر خالد حمدون و عبيدة نزار عبد المنعم

فرع الطب الباطني والوقائي، كلية الطب البيطري، جامعة الموصل، الموصل، العراق الب البن

الخلاصة

هدف التحليل الوبائي الحالي إلى (أ) بيان أمر اض الحيوانات الواردة

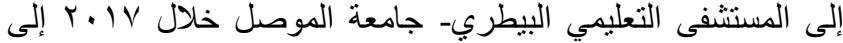

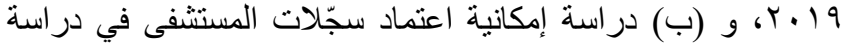

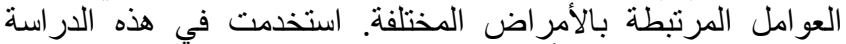

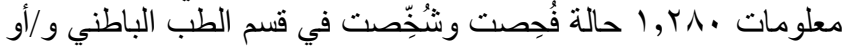
مختبر التشخيصات المرضية. جُمِعت البيانات الوبائية من سجة فيلات المستشفى. استخدام الانحدار اللوجستي الشرطي لنمذجة أرجحية ارتباط

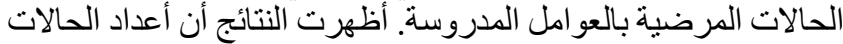

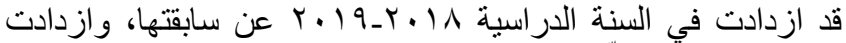

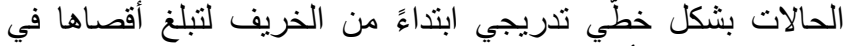

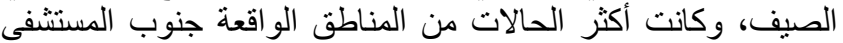

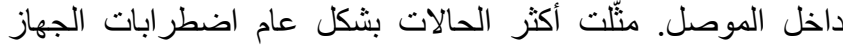

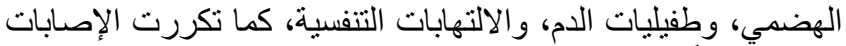

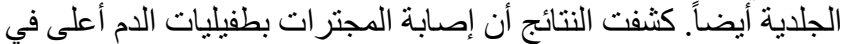

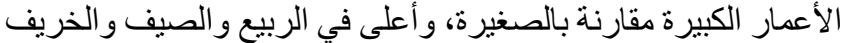

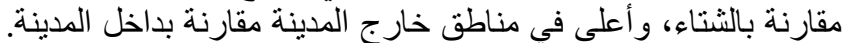
كانت إصابة المجترات بطفيليات المعدة والأمعاء أعلى في في الأعمار

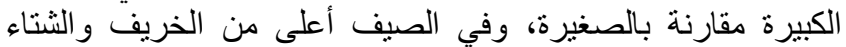

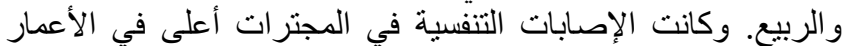

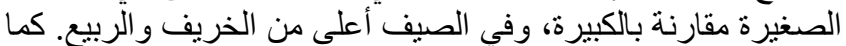

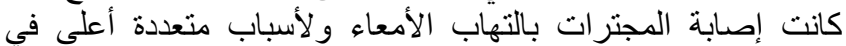

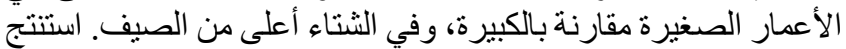

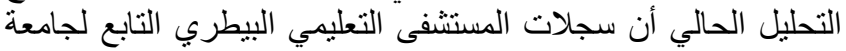

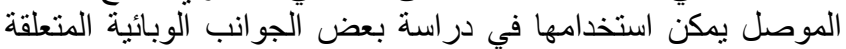
بأمر اض الحيو انات المختلفة. 